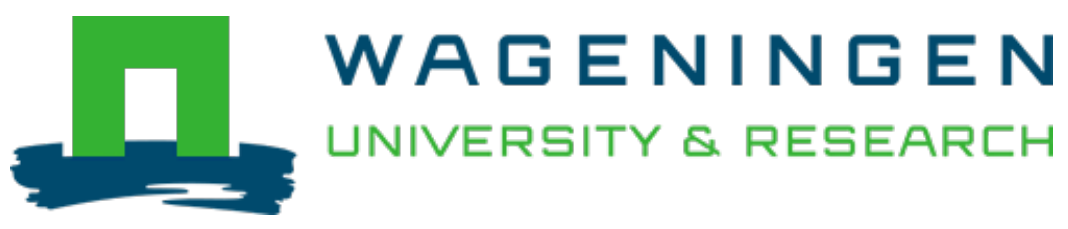

\title{
Ecomorphology of largemouth bass relative to a native trophic analogue explains its high invasive impact
}

\author{
Biological Invasions \\ Luger, A.M.; South, J.; Alexander, M.E.; Ellender, B.R.; Weyl, O.L.F. et al \\ https://doi.org/10.1007/s10530-020-02252-2
}

This article is made publicly available in the institutional repository of Wageningen University and Research, under the terms of article $25 \mathrm{fa}$ of the Dutch Copyright Act, also known as the Amendment Taverne. This has been done with explicit consent by the author.

Article 25 fa states that the author of a short scientific work funded either wholly or partially by Dutch public funds is entitled to make that work publicly available for no consideration following a reasonable period of time after the work was first published, provided that clear reference is made to the source of the first publication of the work.

This publication is distributed under The Association of Universities in the Netherlands (VSNU) 'Article $25 \mathrm{fa}$ implementation' project. In this project research outputs of researchers employed by Dutch Universities that comply with the legal requirements of Article $25 \mathrm{fa}$ of the Dutch Copyright Act are distributed online and free of cost or other barriers in institutional repositories. Research outputs are distributed six months after their first online publication in the original published version and with proper attribution to the source of the original publication.

You are permitted to download and use the publication for personal purposes. All rights remain with the author(s) and / or copyright owner(s) of this work. Any use of the publication or parts of it other than authorised under article $25 \mathrm{fa}$ of the Dutch Copyright act is prohibited. Wageningen University \& Research and the author(s) of this publication shall not be held responsible or liable for any damages resulting from your (re)use of this publication.

For questions regarding the public availability of this article please contact openscience.library@wur.nl 


\title{
Ecomorphology of largemouth bass relative to a native trophic analogue explains its high invasive impact
}

\author{
A. M. Luger $(\mathbb{D} \cdot$ J. South $(\mathbb{D} \cdot$ M. E. Alexander $(\mathbb{D} \cdot$ B. R. Ellender $(\mathbb{D})$ \\ O. L. F. Weyl - L. A. J. Nagelkerke ${ }^{(1)}$
}

Received: 7 June 2019/ Accepted: 21 March 2020

(C) Springer Nature Switzerland AG 2020

\begin{abstract}
Predicting and understanding the impact of biological invaders is a global ecological imperative. Progress has been made through the application of phenomenological analysis via comparative functional response analysis. However, little is known about the mechanisms which drive high-magnitude functional responses of invasive species, especially when compared to trophically analogous natives. Largemouth bass Micropterus salmoides is a freshwater invasive species evaluated as a more efficient
\end{abstract}

Electronic supplementary material The online version of this article (https://doi.org/10.1007/s10530-020-02252-2) contains supplementary material, which is available to authorized users.

A. M. Luger · L. A. J. Nagelkerke

Aquaculture and Fisheries Group, Wageningen University and Research, Wageningen, The Netherlands

A. M. Luger · J. South · M. E. Alexander · B.

R. Ellender · O. L. F. Weyl

South African Institute for Aquatic Biodiversity (SAIAB), Makhanda, South Africa

\section{A. M. Luger}

Evolutionary Morphology of Vertebrates group, Ghent University, Ghent, Belgium

J. South · B. R. Ellender · O. L. F. Weyl

DST-NRF Research Chair in Inland Fisheries and Freshwater Ecology, South African Institute for Aquatic Biodiversity (SAIAB), Makhanda, South Africa predator, with a higher-magnitude functional response, compared to a native analogue, the Cape kurper Sandelia capensis. In order to determine what traits drive this difference we quantified handling time behaviours (detection time, catch time, processing time) of both predator species and prey/predator size ratio, and employ an ecomorphological approach to determine whether largemouth bass is a more specialised predator than Cape kurper. There was no difference in detection time between the species, but largemouth bass were significantly and on average five times faster at catching prey than Cape kurper. Both species' processing time was positively related to prey size, but Cape kurper was on average 4.5 times faster

J. South $(\bowtie) \cdot$ O. L. F. Weyl

Centre for Invasion Biology, SAIAB, Private Bag 1015,

Grahamstown 6140, South Africa

e-mail: j.south@saiab.ac.za

M. E. Alexander

Institute of Biomedical and Environmental Health

Research (IBEHR), School of Science and Sport,

University of West Scotland, High Street,

Paisley PA1 2BE, UK

B. R. Ellender

World Wide Fund for Nature, Lusaka, Zambia 
than largemouth bass. Ecomorphological data indicate that largemouth bass was the more specialised pursuit hunter for fish, whereas Cape kurper was better at ambush hunting. This suggests that the ecological impact of largemouth bass may be exacerbated in areas where there is habitat simplification which can lead to the extirpation of local small-bodied fish. In addition, there may be non-consumptive detrimental effects on trophically analogous natives through competitive exclusion.

Keywords Competition - Functional traits ·

Freshwater $\cdot$ Handling time $\cdot$ Conservation

\section{Introduction}

The continued spread of invasive species across the globe is contributing to biodiversity loss in many ecosystems (Meyerson et al. 2019). As a consequence, invasive species confer substantial economic cost due to the necessity of constant management and mitigation protocols in order to reduce their vast potential ecological effects (Pimental et al. 2005; Oreska and Aldridge 2011; Meyerson et al. 2019). The burden of this makes management somewhat prohibitive, especially within developing countries. Consequently, research has focused on developing predictive methodologies to identify species that will confer the most ecological damage in order to triage potential and emerging invasive species for management purposes (Courtois et al. 2018).

A predictive method that has gained traction is the use of comparative functional response (CFR) analysis (Dick et al. 2014, 2017a,b; Alexander et al. 2014; Dickey et al. 2018). This describes the densitydependent resource utilisation of a consumer (Solomon 1949; Holling 1959) and operates under the assertion that invasive species exert a higher impact, i.e. per capita effect, on resources than native species do (Ricciardi et al. 2013; Dick et al. 2014). In numerous systems, this hypothesis has been experimentally corroborated by showing that successful invasive species do indeed show superior performance with regards to resource utilisation (Dick et al. 2017a,b; Laverty et al. 2017). As the functional response of a species describes resource use in a phenomenological manner [with the functional response relationship being defined by the parameters attack (or search) efficiency $a$, handling (or processing) time $h$, and maximum feeding rate $1 / h$ ]; the causal mechanism of higher ecological impact can only be inferred from the results of functional response experiments. While being a useful tool to describe phenomenological patterns seen in the field and a rapid assessment of relative differences in predation rate, the CFR approach does not give an ultimate cause to explain impacts of invasive species seen in the field.

Predation shapes community structure in ecological systems by controlling the dynamics of predator and prey populations (Sih et al. 1985). In the case that an invasive predator has a higher functional response than the native analogue, it is possible that 1) the invasive species will exert a higher predatory pressure on native prey species and 2) that the population dynamics of shared resources will be disrupted and the native predator will suffer due to being outcompeted by the invader (Alexander et al. 2014; Laverty et al. 2017). Predatory performance (i.e. per capita effect) is affected by a species' physiology, behaviour, hunting strategies, and morphology (Eklöv and Diehl 1994; Takamura 2007; Deurs et al. 2017). These variables drive niche differentiation in species to allow similar species to persist in sympatry. Understanding the way in which invasive species are specialised in comparison to their native analogues can help to inform prediction metrics in order to determine mechanisms that facilitate invasive species impact. Morphological traits ultimately determine the capacity of a species to locate, attack and consume different prey items (Wainwright and Reilly 1994; Sibbing and Nagelkerke 2000), therefore it is an obvious link that these traits contribute to the ecological impact exerted on native species. Dietary overlap and similar trophic profiles, as imbued from morphological trait similarities, of invasive and native species can result in exploitative competition (Nagelkerke et al. 2018). Hence, incorporating an assessment of morphological differences can clarify the causal organismal drivers of high resource consumption and possible out-competition.

The largemouth bass Micropterus salmoides was introduced into South Africa to enhance recreational fisheries (Ellender and Weyl 2014) and has since established in a wide range of habitats throughout the country (Khosa et al. 2019). As a result of its persistence in freshwater systems and high degree of ecological impact it confers on the recipient systems 
(e.g., Weyl et al. 2010; Kimberg et al. 2014; Ellender et al. 2018) it is considered as one of the "World's Worst Invaders" (Lowe et al. 2000). Largemouth bass is a highly efficient piscivore, and while predominantly piscivorous it shows some flexibility in diet preferences (Taylor et al. 2019). In the South African context one of the trophically analogous native species that has been impacted is the Cape kurper Sandelia capensis (Cuvier 1829) (Ellender et al. 2017). Cape kurper is a data-deficient species but has trophic similarities with largemouth bass, being a generalist piscivore with flexible omnivory (Shelton et al. 2018). In most cases, Cape kurper have disappeared from stream reaches invaded by largemouth bass (Ellender et al. 2011).

In assessing the possible mechanism for these exclusions Alexander et al. (2014) used a CFR approach to demonstrate that largemouth bass have a higher-magnitude CFR when feeding on tadpoles compared to Cape kurper, driven by a shorter handling parameter (sensu FR-terminology) resulting in a higher maximum feeding rate (Alexander et al. 2014). In the case of CFR analysis the modelled handling parameter represents and amalgamates a number of linked processes involved in the subduing, consumption, processing and digestion of prey (Jeschke et al. 2002; Sentis et al. 2013). This suggests that largemouth bass have a morphological or physiological advantage over Cape kurper, which facilitates a shorter handling time and allows them to consume more prey items in the same period of time.

This study looks to determine whether there are behavioural and morphological variables driving the high functional response of largemouth bass compared to Cape kurper. Alexander et al. (2014) demonstrated that the handling time parameter drives largemouth bass impact, therefore we empirically quantify the handling time behaviours of largemouth bass compared to Cape kurper. Handling time can be broken down into different behaviours such as time taken to detect, pursue and catch, and actually consume the prey item (Jeschke et al. 2002). This is further affected by the size of the prey item in comparison to the predator (Hoyle and Keast 1986; Kreuzinger-Janik et al. 2019). We employ an ecomorphological approach, i.e. we study the relationships between the ecological role of an individual and its morphological adaptations, to determine whether differences in feeding-related functional traits indicate whether one species is more specialised to particular feeding strategies (Wainwright and Reilly 1994; Sibbing and Nagelkerke 2000; Nagelkerke et al. 2018). This describes the potential niche and preferred prey type of a predator, without considering resource availability or environmental contexts. We hypothesise that due to being more morphologically specialised for piscivory, largemouth bass are more efficient at handling fish prey items than Cape kurper.

\section{Methods}

Animal collection and maintenance

All experiments were completed at the South African Institute for Aquatic Biodiversity in 2013. Largemouth bass $(\mathrm{n}=9 ; 70.2 \pm 4.8 \mathrm{~mm})$ were collected from Jameson Dam (33 $\left.43^{\prime} 04^{\prime \prime} \mathrm{S} ; 26^{\circ} 26^{\prime} 23^{\prime \prime} \mathrm{E}\right)$ and Douglas Dam $\left(33^{\circ} 19^{\prime} 16^{\prime \prime} \mathrm{S} ; 26^{\circ} 31^{\prime} 15^{\prime \prime} \mathrm{E}\right)$ by seine netting and electrofishing. Cape kurper $(n=20$; $59.7 \pm 9.8 \mathrm{~mm}$ ) were collected by seine netting in the Blindekloof stream $\left(33^{\circ} 43^{\prime} 1.42^{\prime \prime} \mathrm{S}\right.$; $\left.25^{\circ} 17^{\prime} 27.41^{\prime \prime} \mathrm{E}\right)$. All sampling was undertaken in March-April 2013. The two species could not be collected from the same location as areas invaded by largemouth bass have experienced extirpations of Cape kurper. The largemouth bass were collected from dams with some rocky littoral structure, but dominated by submerged and emergent vegetation, while the Blindekloof is a small episodic headwater stream dominated shallow rocky substrate with some marginal vegetation and woody debris in-stream.

Cape kurper and largemouth bass were maintained in species-specific, filtered $300 \mathrm{~L}$ holding tanks held at $21 \pm 1.0^{\circ} \mathrm{C}$ under a 16:8 L:D regime prior to handling-time experiments. Fish were acclimated to the focal prey item, female guppies (Poecilia reticulata Peters, 1859) for one week before experimentation and were fed ad libitum once a day. This prey species was chosen because of their general shape, which is very similar to native small-bodied minnows which are natural prey of both predatory species. Further, the native minnows that the guppies represent in this case are highly threatened endemic species which makes using them as prey inconceivable. Guppies were obtained through Hoof and Hound pet store (Makhanda) and maintained in a separate $150 \mathrm{~L}$ holding tank and fed commercial fish flakes (JBL, 
Germany). All experiments were performed under SAIAB Animal Ethics Clearance (2013/02).

\section{Handling time}

Handling time experiments were completed in $65 \mathrm{~L}$ arenas $(25 \mathrm{~L} \times 55 \mathrm{~W} \times 47.5 \mathrm{H} \mathrm{cm})$ with no substrate, filled with aged tap water and held at $21 \pm 1.0^{\circ} \mathrm{C}$. Largemouth bass $(\mathrm{n}=9$; standard length median and range: 71; 63-81 $\mathrm{mm}$ and Cape kurper $(\mathrm{n}=9$; $\mathrm{SL}$ : 56; 45-76 mm) were starved for two days prior to experimentation to standardise hunger levels for the purposes of this experiment. Fish were allowed to acclimate to the experimental arena for $15 \mathrm{~min}$ before introduction of prey. All prey items were individually measured for total length (TL) before use in experiments (TL median and range: 22.5 ; 15.6-37.0 $\mathrm{mm}$ for largemouth bass; 22.5; 15.1-32.4 mm for Cape kurper). There was no significant length difference in prey between the predator groups (Student's $t$ test statistic $t(47)=0.39, \mathrm{p}>0.05)$, although Cape kurper were on average $19 \%$ smaller than largemouth bass (56.8 vs. $70.2 \mathrm{~mm}$, Student's t-test statistic $t(16)=3.82, \mathrm{p}<0.05)$. To correct for size differences between and among predators and prey, we used the prey-predator size ratio (defined as the ratio of the TL of the prey and the SL of the predator). Predators were allowed $30 \mathrm{~min}$ to feed, after which the experiment was terminated even if predation had not occurred. Each individual fish was tested three times with a repeated measures design to reduce number of animals needed, which was especially important considering the declining abundance of Cape kurper in the wild (Ellender et al. 2011; Shelton et al. 2017; Ellender et al. 2018). All trials were filmed using GoPro Hero 1 HD video cameras. Video recordings were then reviewed to determine exact times for: (1) prey detection; (2) catching the prey; and (3) processing the prey.

Detection time $\left(t_{\text {det }}\right)$ was defined as the time between prey release into the tank and detection of the prey by the predator. The moment of detection could be clearly observed, through increased alert behaviour of the predator, after which it either engaged in pursuit or not. Catch time $\left(\mathrm{t}_{\mathrm{cat}}\right)$ was the time between the moment the predator started its pursuit, until the moment of capture of the prey. Finally, processing time $\left(t_{\mathrm{pr}}\right)$ was the time between the moment of catch and swallowing of the prey.
Processing of the prey was externally visible, through head movements indicating repositioning and chewing of the prey in the mouth. The moment these head movements stopped, processing of the prey was complete, and the prey was swallowed.

Time data were log-transformed and linear mixedeffects models were fitted, based on maximum likelihood. "Predator species" and "prey-predator size ratio" were used as fixed factors, while "individual fish" was used as a random factor. To account for repeated measures (several experiments were performed with each individual fish), "individual fish" was nested within "predator species". For each handling component separately, a full model was fitted, containing "predator species", "prey-predator size ratio", and their interaction. Non-significant terms were removed stepwise from the model, starting with the interaction term. The final model only contained significant terms. Model residuals were checked for normality through visual inspection of QQ plots and Shapiro-Wilk tests, and for homogeneity between groups with Levene's tests. All analyses were performed in an R environment (R Core Team, 2018), using the package nlme (Pinheiro et al. 2018).

\section{Ecomorphology}

Feeding-associated functional morphological traits were measured to compare the trophic capacities of largemouth bass and Cape kurper according to (Sibbing and Nagelkerke 2000) (Table 1). The same fish were used for ecomorphological analysis and for the handling time experiment to reduce the number of animals (SL median and range largemouth bass $(\mathrm{n}=9): 71 ; 63-81 \mathrm{~mm}$, Cape kurper $(\mathrm{n}=20)$ : 58 ; 45-78 mm). Fish were euthanized with an overdose of clove oil (400 mg/L) and frozen before morphological traits were measured. Traits were selected because they are related to the fish's capacity to prey on particular aquatic prey types, and because they were suitable for the two focal species of this study. Measurements were performed using a standard dissection kit, a set of callipers (Sylvac) for length measurements, and a dissection microscope.

\section{Analysis}

Fifteen feeding-associated functional traits were measured according to (Sibbing and Nagelkerke 2000) 
Table 1 Feeding-associated, morphological traits and their units. Definitions follow (Sibbing and Nagelkerke 2000) and Nagelkerke et al. (2018)

\begin{tabular}{ll}
\hline Morphological trait & Unit \\
\hline Anal fin area & $\mathrm{mm}^{2}$ \\
Body depth & $\mathrm{mm}$ \\
Body depth/width & ratio \\
Caudal peduncle depth & $\mathrm{mm}$ \\
Eye diameter & $\mathrm{mm}$ \\
Gape size & $\mathrm{mm}^{2}$ \\
Head length & $\mathrm{mm}$ \\
Hyoid length & $\mathrm{mm}$ \\
Lower jaw closing force efficiency & $\mathrm{ratio}$ \\
Lower jaw length & $\mathrm{mm}$ \\
Opercular volume capacity & $\mathrm{ratio}$ \\
Operculum area & $\mathrm{mm}$ \\
Palatal organ area & $\mathrm{mm}$ \\
Relative gape area & ratio \\
Velocity suction capacity & ratio \\
\hline
\end{tabular}

(Table 1). Linear and surface area measures were scaled by taking the residuals of the linear regressions of the log-transformed measures on the log-transformed standard length (SL), while for ratios there was no need for scaling (Nagelkerke et al. 2018). The foodfish model (FFM), as described in (Sibbing and Nagelkerke 2000), was used to systematically and quantitatively relate functional traits of each individual fish to its capacity to utilize aquatic prey types. This was done in two steps. First the effects of morphological traits on the capacity to eat a suite of aquatic food resources were established and quantitatively expressed as positive, negative, or zero values (ranging between -2 and +2 , with zero values indicating that there is no known evidence for an effect). The combined values of all such effects for an aquatic resource form a hypothetical "food specialist profile" (FSP), expressing the ideal relative sizes of morphological traits to exploit that resource (S1). The FSP values for each aquatic food resource were correlated with the morphological measurements of each individual fish (Kendall's tau correlation), resulting in a correlation coefficient which is considered a measure of the predicted capacity of the fish to feed on this particular food resource. Differences between species in their predicted feeding capacities on particular aquatic food resources were tested with a Wilcoxon rank sum test, to avoid problems with nonnormal residuals. The combined series of these correlation coefficients for all aquatic food resources was called a trophic profile (TP). The values of measured morphological traits and values of FSPs, were separately standardized before correlation (subtracting the mean value of each variable and dividing by the standard deviation), resulting in a mean value of zero and a standard deviation of one for each variable, thus giving equal weight to all variables (Nagelkerke et al. 2018).

Principal components analysis (PCA) was performed on the functional feeding traits to compare overall trophic morphology, as well as on the TPs for an overall interpretation of trophic capacities. All statistics were performed in an R environment ( $\mathrm{R}$ Core Team 2018).

\section{Results}

\section{Handling Times}

Detection time $\left(\mathrm{t}_{\mathrm{det}}\right)$ did not vary with predator species $(b=0.87(\mathrm{SE}=0.69), t(10)=1.26, P=0.24)$ nor with prey- predator ratio $(b=-5.20(\mathrm{SE}=4.01)$, $t(15)=-1.30, P=0.21)$ and was estimated to have a geometric mean value of $6.1 \mathrm{~s}$ (95\% CI: 3.3-11.2 s; Fig. 1a). Largemouth bass had a significantly faster $t_{\text {cat }}$ than Cape kurper $(b=1.73(\mathrm{SE}=0.33), \mathrm{t}(10)=5.22$, $P<0.0001$; Fig. 1b) but prey-predator size ratio did not have a significant effect on $\mathrm{t}_{\mathrm{cat}}(b=0.22$ ( $\mathrm{SE}=$ 2.39), $t(14)=0.09, P=0.93$; Fig. 1b). Geometric mean of $\mathrm{t}_{\text {cat }}$ for largemouth bass was $2.0 \mathrm{~s}(95 \% \mathrm{CI}$ : 1.3-3.0 s) and $11.1 \mathrm{~s}(95 \% \mathrm{CI}: 6.9$ - $17.9 \mathrm{~s})$ for Cape kurper. Processing time $\left(\mathrm{t}_{\mathrm{pr}}\right)$ was significantly, and on average 4.5 times, shorter for Cape kurper $(b=-1.17 \quad(\mathrm{SE}=0.25), \quad t(10)=-4.76$, $P<0.001)$, and significantly increased with preypredator size ratio for both species $(b=10.82$ ( $\mathrm{SE}=$ 1.52), $t(13)=7.12, P<0.0001$; Fig. 1c). ShapiroWilk normality tests indicated that the residuals of the final models were not deviating from a normal distribution in case of $t_{\text {cat }}$ and $t_{p r}$. For $t_{\text {det }}$ the Shapiro-Wilk test indicated a deviation from a normal distribution, but visual inspection of the Q-Q plots did not. Levene's tests indicated that for all models residuals were homogeneously distributed. 

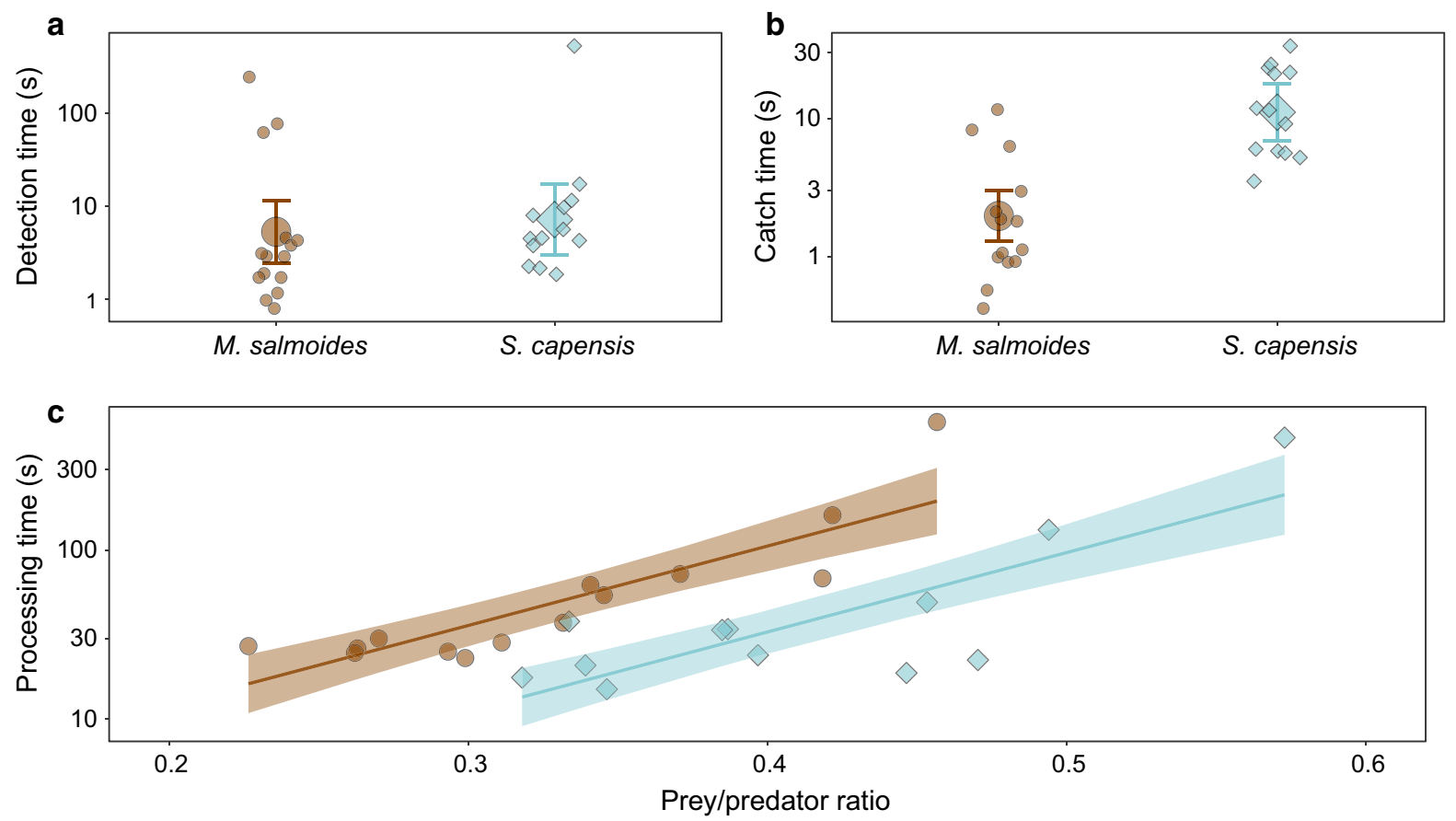

Fig. 1 a Overall geometric mean and $95 \%$ confidence interval of detection time, b Geometric mean and 95\%-confidence interval of catch time c Processing time in relation to prey/

\section{Ecomorphology}

The PCA of the morphological variables explained $61.0 \%$ of variance along the first and second axes (Fig. 2a,b). Overall the morphologies of largemouth bass and Cape kurper were clearly separate along the first axis, while still showing considerable intraspecific variation along the first and second axis (Fig. 2a,b). Relative gape area, hyoid length and velocity suction capacity were larger in largemouth bass, while in Cape kurper anal fin area, caudal peduncle depth, and operculum area were clearly larger.

Differences in trophic morphology translated in clear differences in TPs. The PCA of TPs $(85.9 \%$ of the total variation explained along the first two axes: Fig. $2 \mathrm{c}, \mathrm{d}$ ) revealed that largemouth bass is predicted to be a more specialised pursuit hunter, while Cape kurper is better equipped for ambush hunting and for the exploitation of a wide variety of (smaller-bodied) prey, although there is considerable intra-specific variation. Except for macro-crustaceans, TPs were significantly different between species for all prey types (Wilcoxon rank sum test, $P<0.05$; Fig. 3 ). predator size ratio with $95 \%$-confidence intervals. Individual values for Micropterus salmoides indicated by brown circles, and for Sandelia capensis by blue diamonds

\section{Discussion}

Predicting and understanding the factors that drive higher ecological impact of invasive species is one of the major challenges and priorities in invasion ecology. While phenomenological methods have proven insightful in predicting which species are likely to cause damage to native biodiversity, the actual mechanisms responsible for ecological impacts remain a black box. We demonstrate here, that by combining an ecomorphological mechanistic approach on the back of a phenomenological approach (such as the handling time experiment here, or the conventional CFR approach:Alexander et al. 2014; Dick et al. 2017), it is possible to specify what traits are instrumental in the interactions between species and potentially contribute to the invasion success and detrimental effects of a global invader.

Time taken to handle prey determines how much a predator can eat within a given period of time. Quantifying differences in handling time behaviours is consequently a powerful way to distinguish between the efficiency of trophically analogous predators. In this case, there was no difference in the time taken to 

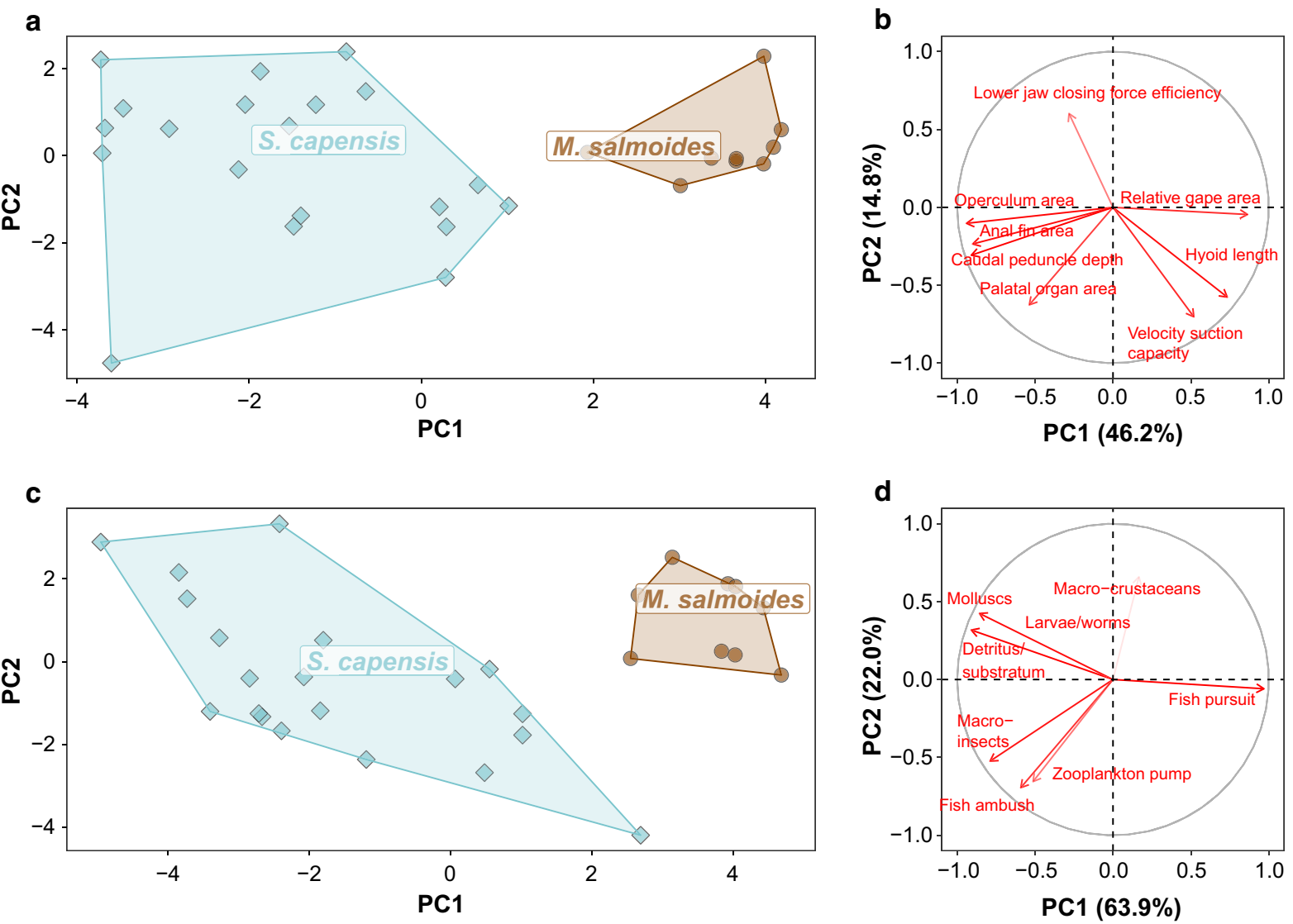

Fig. 2 Biplot of a principal component analysis (PCA) of trophic morphological traits $(\mathrm{a}, \mathrm{b})$ and of derived trophic profiles (TP: c,d). Markers in the left graphs indicate individual fish belonging to Sandelia capensis (blue diamonds) or Micropterus

detect prey items between the two predators, therefore predatory efficiency was driven by differences in capability of physically handling and processing the prey items (Jeschke et al. 2002). Nonetheless, this may have been driven by the size of the arena and limited complexity within the arena used in order to film the interactions without obstacle. Prey size was a limiting factor for both species where the larger the prey were, the longer it took for the fish to handle, with regards to catching and processing time. This result is intuitive, given gape size restrictions and ability of the prey to escape (Howick and O'Brien 1983; Gaeta et al. 2018). However, Cape kurper had a faster processing time than largemouth bass, which may make up for its comparatively poor catch rate when preying upon highly abundant prey.

The use of handling time experiments can lead to a better understanding of the feeding process and its salmoides (brown circles). Arrows in the right graphs indicate the loadings of the most influential variables on the PC-axes. Convex hulls show that there is no overlap between the two species

constituent components (detection, catch, and processing), which could potentially serve as an addition to, or an alternative, for the functional-response approach. Moreover, by detailed study of the handling time, probably fewer prey animals are necessary than in the comparative functional response approach. In addition, the ecomorphological approach could be used to predict potential interactions between alien and native species before they actually occur, because the approach gives insights in the potential diet breadth and potential trophic overlap (Nagelkerke et al. 2018) and thus could be used as a "horizonscanning" tool (Gallardo et al. 2016).

Largemouth bass are a major driver of fish community structure (Jackson 2002) and cause considerable damage to native biota in their invaded ranges (Takamura 2007; Kimberg et al. 2014; Ellender et al. 2018). This is evidently due to their higher 


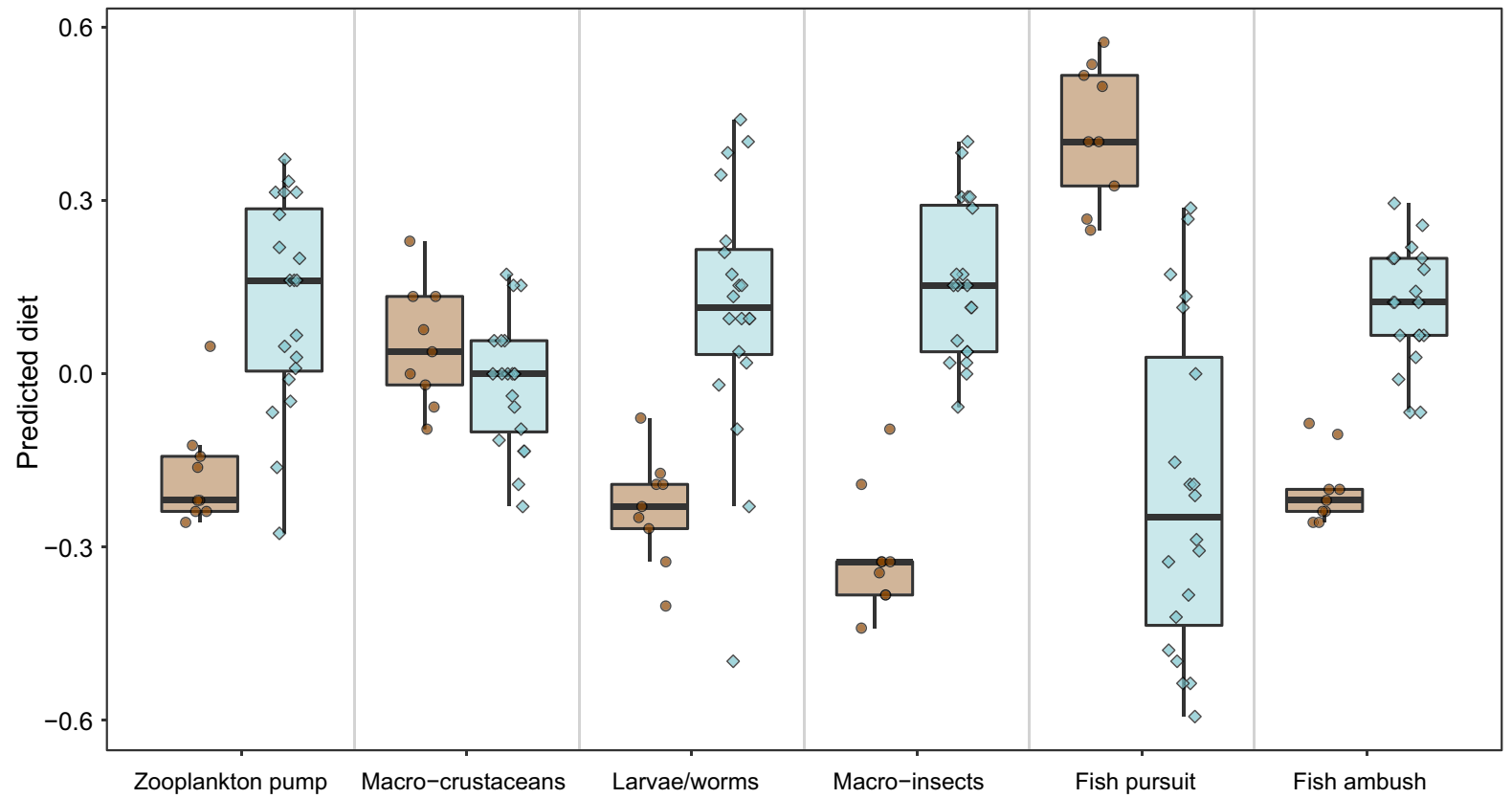

Fig. 3 Correlations of predicted diet specialisations from the food-fish model (Sibbing and Nagelkerke 2000) for Micropterus salmoides (brown) and Sandelia capensis (blue). Horizontal lines indicate the median value, boxes show the $25-75 \%$

degree of resource exploitation in comparison to native species (Alexander et al. 2014; Alexander et al. 2015). Our results corroborate that largemouth bass are indeed superior piscivores, in comparison to Cape kurper, due to their ecomorphological traits facilitating active pursuit hunting styles (Sullivan and Atchison 1978). Despite Cape kurper having feeding behaviour similar to juvenile centrarchids, i.e. on invertebrates and small fish (Gosse Gosse 1986; Skelton 2001; Shelton et al. 2018), their morphology indicates that they are less specialised in terms of active piscivory than largemouth bass. This implies that Cape kurper performs better in environments with a higher habitat complexity, which is in contrast to largemouth bass which performs better in simplified habitats, especially when feeding on fish prey (Alexander et al. 2015; Shoup and Broderius 2018; Tsunod and Mitsuo 2018). Nonetheless, as the present study and the study by Alexander et al. (2014) both used juvenile largemouth bass, it is important to stress that there can be ontogenetic switches in feeding behaviour that are driven both by individual size, but quantile. Differences between species are all statistically significant $(P<0.05)$, except for macro-crustaceans. Only the six most important prey types (of 14) are shown for clarity

also by habitat and environmental factors (GarcíaBerthou 2002; Post 2003; Tsunoda and Mitsuo 2018).

These results give, for the first time, a mechanistic explanation of the process in which juvenile largemouth bass are able to outcompete native species, while, when they are fully grown, they simply directly prey upon Cape kurper. They exert non-consumptive effects upon adult Cape kurper by being superior fish predators (Alexander et al. 2014), but also have a direct consumptive effect on fish prey (Alexander et al. 2014; Shoup and Broderius 2018). Cape kurper are generalist piscivorous fish, but have the potential to show omnivory depending on the need for resource portioning within a system (Shelton et al. 2018). It is possible that a combination of pressure exerted by a more efficient piscivore (i.e. largemouth bass) could drive dietary shift in Cape kurper to less optimal resources, such as invertebrate prey, but also changes in habitat associations (Bøhn and Amundsen 2001).

South African streams have a high degree of endemicity which makes them priority conservation areas (Weyl et al. 2014; Ellender et al. 2017). Largemouth bass consistently cause extirpations of 
small-bodied, cyprinid minnows, many of which cooccur with Cape kurper (Ellender et al. 2017; Ellender et al. 2018). Field behavioural observations by Ellender et al. (2018) of Eastern Cape redfin Pseudobarbus afer which co-occurs with Cape kurper in its native range, demonstrated that they foraged among benthic cover during the day, but suspended motionless in open water at night. While this was interpreted as a strategy to avoid predation by native anguillid predators, our data suggest that this strategy may also mediate predation by Cape kurper. While the morphology of Cape kurper certainly does not prevent it from preying on small endangered minnow species, it is more effective as an ambush than as a pursuit hunter (Shelton et al. 2018). This exposes the mechanism within which centrarchids exert direct and indirect pressure upon South African native fishes and furthers the need to restore and manage degraded ecosystems to increase habitat complexity. These findings support the necessity to develop impact prediction methods further by combining phenomenological metrics, such as CFR and handling time experiments, with empirical morphological methods such as the fish-food model to fully understand the interplay of traits that drive population dynamics in the field.

Acknowledgements The authors acknowledge the use of infrastructure and equipment provided by the SAIAB Research Platform and funding channelled through the NRFSAIAB Institutional Support system. This work was financially and logistically supported by the National Research Foundation (NRF) of South Africa, DST-NRF - South African Research Chairs Initiative of the Department of Science and Technology (Grant No. 110507), the DST-NRF Centre of Excellence in Invasion Biology and Rhodes University. The research that this publication is based on was conducted according to protocols which comply with the ethical standards of the South African Institute for Aquatic Biodiversity. Permits for field surveys were issued by the Department of Economic Development and Environmental Affairs (DEDEA; permit no. CRO16/10CR, CRO 17/10) and Eastern Cape Parks Board. Eastern Cape Parks Board and the staff of the Groendal Wilderness Area are thanked for access and for their logistical assistance.

Author contributions AML, LAJN, BRE, MEA, OLFW conceived and designed the study. AML collected data. JS and LAJN analysed the data. JS and LAJN led the writing of the manuscript. AML, JS, LAJN, BRE, MEA, OLFW contributed to editing and content of the manuscript.

\section{Compliance with ethical standard}

Conflicts of interest The authors have no conflict of interest to declare.

\section{References}

Alexander ME, Dick JTA, Weyl OLF, Robinson TB, Richardson DM (2014) Existing and emerging high impact invasive species are characterized by higher functional responses than natives. Biol Lett 10:20130946. https://doi. org/10.1098/rsbl.2013.0946

Alexander ME, Kaiser H, Weyl OLF, Dick JTA (2015) Habitat simplification increases the impact of a freshwater invasive fish. Environ Biol Fishes 98(2):477-486. https://doi.org/ 10.1007/s10641-014-0278-Z

Bøhn T, Amundsen PA (2001) The competitive edge of an invading specialist. Ecology 82:2150-2163. https://doi. org/10.1890/0012-9658(2001)082\%5b2150:TCEOAI\% 5d2.0.CO;2

Courtois P, Figuieres C, Mulier C, Weill J (2018) A Cost-benefit approach for prioritizing invasive species. Ecol Econ 146:607-620. https://doi.org/10.1016/j.ecolecon.2017.11. 037

Deurs MV, Andersson A, Vinterstare J, Didenko A, Persson A, Brönmark C, Nilsson PA (2017) Using accelerometry to quantify prey attack and handling behaviours in piscivorous pike Esox lucius. J Fish Biol 90:2462-2469. https:// doi.org/10.1111/jfb. 13310

Dick JTA, Alexander ME, Jeschke JM, Ricciardi A, MacIsaac HJ, Robinson TB, Kumschick S, Weyl OLF, Dunn AM, Hatcher MJ, Paterson RA, Farnsworth KD, Weyl OLF, Richardson DM (2014) Advancing impact prediction and hypothesis testing in invasion ecology using a comparative functional response approach. Biol Invasions 16:735-753. https://doi.org/10.1007/s10530-013-0550-8

Dick JTA, Alexander ME, Ricciardi A, Laverty C, Downey PO, $\mathrm{Xu}$ M, Jeschke JM, Saul W-C, Hill MP, Wasserman R, Barrios-O'Neill D, Weyl OLF, Shaw RH (2017a) Functional responses can unify invasion ecology. Biol Invasions 19:1667-1672. https://doi.org/10.1007/s10530-016-13553

Dick JTA, Laverty C, Lennon JJ, Barrios-O’Neill D, Mensink PJ, Britton JR, Médoc V, Boets P, Alexander ME, Taylor NG, Dunn AM, Hatcher MJ, Rosewarne PJ, Crookes S, MacIsaac HJ, Xu M, Ricciardi A, Wasserman RJ, Ellender BR, Weyl OLF, Lucy FE, Banks PB, Dodd JA, MacNeil C, Penk MR, Aldridge DC, Caffrey JM (2017b) Invader Relative Impact Potential: a new metric to understand and predict the ecological impacts of existing, emerging and future invasive alien species. J Appl Ecol 54:1259-1267

Dickey JWE, Cuthbert RN, Rea M, Laverty C, Crane K, South J, Briski E, Chang X, Coughlan NE, MacIsaac HJ, Ricciardi A, Riddell GE, Xu M, Dick JTA (2018) Assessing the relative potential ecological impacts and invasion risks of emerging and future invasive alien species. NeoBiota 40:1-24. https://doi.org/10.3897/neobiota.40.28519

Eklöv P, Diehl S (1994) Piscivore efficiency and refuging prey: the importance of predator search mode. Oecologia 98:344-353. https://doi.org/10.1007/BF00324223

Ellender B, Weyl O (2014) A review of current knowledge, risk and ecological impacts associated with non-native freshwater fish introductions in South Africa. Aquat Invasions 9:117-132. https://doi.org/10.3391/ai.2014.9.2.01 
Ellender BR, Weyl OLF, Swartz ER (2011) Invasion of a headwater stream by non-native fishes in the Swartkops River system, South Africa. Afr Zool 46:39-46. https://doi. org/10.1080/15627020.2011.11407477

Ellender BR, Wasserman RJ, Chakona A, Skelton PH, Weyl OLF (2017) A review of the biology and status of Cape Fold Ecoregion freshwater fishes. Aquat Conserv Mar Freshw Ecosyst 27:867-879. https://doi.org/10.1002/aqc. 2730

Ellender BR, Weyl OLF, Alexander ME, Luger AM, Nagelkerke LAJ, Woodford DJ (2018) Out of the pot and into the fire: explaining the vulnerability of an endangered small headwater stream fish to black-bass Micropterus spp. invasion. J Fish Biol 92:1035-1050. https://doi.org/10. $1111 /$ jfb. 13562

Gaeta JW, Ahrenstorff TD, Diana JS, Fetzer WW, Jones TS, Lawson ZJ, McInerny MC Jr, Santucci VJ, Zanden MJV (2018) Go big or ... don't? A field-based diet evaluation of freshwater piscivore and prey fish size relationships. PLoS ONE 13:e0194092. https://doi.org/10.1371/journal.pone. 0194092

Gallardo B, Zieritz A, Adriaens T, Bellard C, Boets P, Britton JR, Newman JR, van Valkenburg JLCH, Aldridge DC (2016) Trans-national horizon scanning for invasive nonnative species: a case study in western Europe. Biol Invasions 18:17-30. https://doi.org/10.1007/s10530-015-09860

García-Berthou E (2002) Ontogenetic diet shifts and interrupted piscivory in introduced largemouth bass (Micropterus salmoides). Int Rev Hydrobiol 87:353-363. https://doi.org/ 10.1002/1522-2632(200207)87:43.0.CO;2-N

Gosse J-P (1986) Anabantidae, p. 402-414. In J. Daget, J-P. Gosse and D.F.E. Thys van den Audenaerde (eds.) Checklist of the freshwater fishes of Africa (CLOFFA). ISNB, Brussels; MRAC, Teryuren; and ORSTOM, Paris. Vol. 2

Holling CS (1959) Some characteristics of simple types of predation and parasitism. Can Entomol 91:385-398

Howick GL, O’Brien WJ (1983) Piscivorous feeding behavior of largemouth bass: an experimental analysis. Trans Am Fish Soc 112:508-516. https://doi.org/10.1577/15488659(1983)112\%3c508:PFBOLB\%3e2.0.CO;2

Hoyle JA, Keast A (1986) The effect of prey morphology and size on handling time in a piscivore, the largemouth bass (Micropterus salmoides). Can J Zool 65:1972-1977. https://doi.org/10.1139/z87-300

Jackson DA (2002) Ecological effects of Micropterus introductions: the dark side of black bass. Pages 221-232 In: Philipp DP, Ridgway MS (ed). Black bass: ecology, conservation, and management. American Fisheries Society Symposium 31, Bethesda,

Jeschke JM, Kopp M, Tollrian R (2002) Predator functional responses Discriminating between handling and digesting prey. Ecol Monogr 72:95-112. https://doi.org/10.1890/ 0012-9615(2002)072\%5b0095:PFRDBH\%5d2.0.CO;2

Khosa D, Marr SM, Wasserman RJ, Zengeya TA, Weyl OLF (2019) An evaluation of the current extent and potential spread of Black Bass invasions in South Africa. Biol Invasions 21:1721-1736. https://doi.org/10.1007/s10530019-01930-0

Kimberg PK, Woodford DJ, Roux H, Weyl OLF (2014) Speciesspecific impact of introduced largemouth bass Micropterus salmoides in the Groot Marico Freshwater Ecosystem Priority Area, South Africa. Afr J Aquat Sci 39:451-458. https://doi.org/10.2989/16085914.2014.976169

Kreuzinger-Janik B, Hüttemann HB, Traunspurger W (2019) Effect of prey size and structural complexity on the functional response in a nematode- nematode system. Sci Rep 9:5696. https://doi.org/10.1038/s41598-019-42213-x

Laverty C, Green KD, Dick JTA, Barrios D, Mensink PJ, Médoc V, Spataro T, Caffrey JM, Lucy FE, Boets P, Britton JR, Pegg J, Gallagher C (2017) Assessing the ecological impacts of invasive species based on their functional responses and abundances. Biol Invasions 19:165-1665

Lowe S, Browne M, Boudjelas S, De Poorter M (2000) 100 of the World's Worst Invasive Alien Species A selection from the Global Invasive Species Database. Published by The Invasive Species Specialist Group (ISSG) a specialist group of the Species Survival Commission (SSC) of the World Conservation Union (IUCN), 12 pp. First published as a special lift-out in Aliens 12, December 2000

Meyerson LA, Carlton JT, Simberloff D, Lodge DM (2019) The growing peril of biological invasions. Front Ecol Environ 17:191. https://doi.org/10.1002/fee.2036

Nagelkerke LAJ, van Onselen E, van Kessel N, Leuven RSEW (2018) Functional feeding traits as predictors of invasive success of alien freshwater fish species using a food-fish model. PLoS ONE 13:e0197636. https://doi.org/10.1371/ journal.pone.0197636

Oreska MPJ, Aldridge DC (2011) Estimating the financial costs of freshwater invasive species in Great Britain: a standardized approach to invasive species costing. Biol Invasions 13:305-319. https://doi.org/10.1007/s10530-0109807-7

Pimentel D, Zuniga R, Morrison D (2005) Update on the environmental and economic costs associated with alien-invasive species in the United States. Ecol Econ 52:273-288. https://doi.org/10.1016/j.ecolecon.2004.10.002

Pinheiro J, Bates D, DebRoy S, Sarkar D, R Core Team (2018) _nlme: Linear and Nonlinear Mixed Effects Models_. R package version 3.1-131.1. https://CRAN.R-project.org/ package $=$ nlme. Accessed Apr 2019

Post DM (2003) Individual variation in the timing of ontogenetic niche shifts in largemouth bass. Ecology 84: 1298-1310. JSTOR, www.jstor.org/stable/3107938. Accessed 14 Jan 2020

Ricciardi A, Hoopes MF, Marchetti MP, Lockwood JL (2013) Progress toward understanding the ecological impacts of nonnative species. Ecol Monogr 83:263-282. https://doi. org/10.1890/13-0183.1

R Core Team (2018) R: A language and environment for statistical computing. R Foundation for Statistical Computing, Vienna, Austria. https://www.R-project.org/. Accessed Apr 2019

Sentis A, Hemptinne J-L, Brodeur J (2013) Parsing handling time into its components: implications for responses to a temperature gradient. Ecology 94:1675-1680. https://doi. org/10.1890/12-2107.1

Shelton JM, Impson ND, Graham S, Esler KJ (2017) Down, but not out: recent decline of Berg-Breede River whitefish (Barbus andrewi) in the upper Hex River. S Afr Koedoe 59:6. https://doi.org/10.4102/koedoe.v59i1.1398 
Shelton JM, Bird MS, Marr SM (2018) Evidence for diet partitioning among three coexisting native freshwater fishes in South Africa's Cape Fold Ecoregion. Afr J Aquat Sci 43:89-100. https://doi.org/10.2989/16085914.2018.1470490

Shoup DE, Broderius CR (2018) Effects of vegetation density on the ontogeny to piscivory of juvenile largemouth bass. N Am J Fish Manag 38:630-638. https://doi.org/10.1002/ nafm. 10060

Sibbing FA, Nagelkerke LAJ (2000) Resource partitioning by Lake Tana barbs predicted from fish morphometrics and prey characteristics. Rev Fish Biol Fish 10:393-437. https://doi.org/10.1023/A:1012270422092

Sih A, Crowley P, McPeek M, Petranka J, Strohmeier K (1985) Predation, competition, and prey communities: a review of field experiments. Annu Rev Ecol Syst 16:269-311. https:// doi.org/10.1146/annurev.es.16.110185.001413

Solomon ME (1949) The Natural control of animal populations. J Anim Ecol 18:1-35

Sullivan JF, Atchison GJ (1978) Predator-prey behaviour of fathead minnows, Pimephales promelas and largemouth bass, Micropterus salmoides in a model ecosystem. J Fish Biol 13:249-253. https://doi.org/10.1111/j.1095-8649. 1978.tb03432.x

Takamura K (2007) Performance as a fish predator of largemouth bass [Micropterus salmoides (Lacepède)] invading Japanese freshwaters: a review. Ecol Res 22:940-946. https://doi.org/10.1007/s11284-007-0415-7
Taylor GC, Hill JM, Weyl OLF (2019) The diet and trophic ecology of non-native Micropterus salmoides in two South African impoundments. Afr J Aquat Sci 44:143-153. https://doi.org/10.2989/16085914.2019.1612318

Tsunoda H, Mitsuo Y (2018) Variations in piscivory of invasive largemouth bass Micropterus salmoides associated with pond environments. Limnology 19:271-276. https://doi. org/10.1007/s10201-018-0544-4

Wainwright PC, Reilly SM (1994) Ecological morphology: integrative organismal biology. The University of Chicago Press, Chicago, p 367

Weyl PS, de Moor FC, Hill MP, Weyl OLF (2010) The effect of largemouth bass Micropterus salmoides on aquatic macroinvertebrate communities in the Wit River, Eastern Cape, South Africa. Afr J Aquat Sci 35:273-281. https://doi.org/ 10.2989/16085914.2010.540776

Weyl OLF, Finlayson B, Impson ND, Woodford DJ, Steinkjer J (2014) Threatened endemic fishes in South Africa's Cape Floristic Region: a new beginning for the Rondegat river. Fisherie 39:270-279. https://doi.org/10.1080/03632415. 2014.914924

Publisher's Note Springer Nature remains neutral with regard to jurisdictional claims in published maps and institutional affiliations. 